\title{
Human mass balance study of the novel anticancer agent ixabepilone using accelerator mass spectrometry
}

\author{
J. H. Beumer • R. C. Garner • M. B. Cohen • \\ S. Galbraith • G. F. Duncan • T. Griffin • J. H. Beijnen • \\ J. H. M. Schellens
}

Received: 10 January 2007 / Accepted: 8 February 2007 / Published online: 9 March 2007

(C) Springer Science + Business Media, LLC 2007

\begin{abstract}
Summary Ixabepilone (BMS-247550) is a semi-synthetic, microtubule stabilizing epothilone B analogue which is more potent than taxanes and has displayed activity in taxane-resistant patients. The human plasma pharmacokinetics of ixabepilone have been described. However, the excretory pathways and contribution of metabolism to ixabepilone elimination have not been determined. To investigate the elimination pathways of ixabepilone we initiated a mass balance study in cancer patients. Due to autoradiolysis, ixabepilone proved to be very unstable when labeled with conventional $\left[{ }^{14} \mathrm{C}\right]$-levels $(100 \mu \mathrm{Ci}$ in a
\end{abstract}

\footnotetext{
J. H. Beumer · J. H. Beijnen

Department of Pharmacy \& Pharmacology, Slotervaart Hospital/

The Netherlands Cancer Institute,

Amsterdam, The Netherlands

J. H. Beumer $(\square)$

University of Pittsburgh Cancer Institute,

Suite G27D, Hillman Research Pavilion, 5117 Centre Avenue,

Pittsburgh, PA 15213, USA

e-mail: BEUMERJH@UPMC.EDU

R. C. Garner

Xceleron, York, UK

M. B. Cohen · S. Galbraith • G. F. Duncan · T. Griffin

Bristol-Myers Squibb Clinical Discovery,

Princeton, NJ, USA

J. H. Beijnen · J. H. M. Schellens

Department of Biomedical Analysis, Division of Drug

Toxicology, Faculty of Pharmaceutical Sciences,

Utrecht University, Utrecht, The Netherlands
}

J. H. M. Schellens

Department of Medical Oncology, Antoni van Leeuwenhoek

Hospital/The Netherlands Cancer Institute,

Amsterdam, The Netherlands typical human radio-tracer study). This necessitated the use of much lower levels of $\left[{ }^{14} \mathrm{C}\right]$-labeling and an ultrasensitive detection method, Accelerator Mass Spectrometry (AMS). Eight patients with advanced cancer (3 males, 5 females; median age $54.5 \mathrm{y}$; performance status $0-2$ ) received an intravenous dose of $70 \mathrm{mg}, 80 \mathrm{nCi}$ of $\left[{ }^{14} \mathrm{C}\right]$ ixabepilone over $3 \mathrm{~h}$. Plasma, urine and faeces were collected up to 7 days after administration and total radioactivity (TRA) was determined using AMS. Ixabepilone in plasma and urine was quantitated using a validated LC-MS/MS method. Mean recovery of ixabepilone-derived radioactivity was $77.3 \%$ of dose. Fecal excretion was $52.2 \%$ and urinary excretion was $25.1 \%$. Only a minor part of TRA is accounted for by unchanged ixabepilone in both plasma and urine, which indicates that metabolism is a major elimination mechanism for this drug. Future studies should focus on structural elucidation of ixabepilone metabolites and characterization of their activities.

Keywords Ixabepilone · Epothilone · Mass balance . Accelerator mass spectrometry $\cdot$ Anti-cancer agent

\begin{tabular}{|c|c|}
\hline \multicolumn{2}{|c|}{ Abbreviations } \\
\hline AMS & Accelerator mass spectrometry \\
\hline AUC & $\begin{array}{l}\text { Area under the plasma concentration versus } \\
\text { time curve }\end{array}$ \\
\hline $\mathrm{AUC}_{\mathrm{inf}}$ & AUC extrapolated to infinity \\
\hline $\mathrm{AUC}_{\text {last }}$ & $\begin{array}{l}\text { AUC until the time of the last quantifiable } \\
\text { measurement }\end{array}$ \\
\hline $\mathrm{AUMC}_{\text {inf }}$ & $\begin{array}{l}\text { Area under the first moment versus time } \\
\text { curve extrapolated to infinity }\end{array}$ \\
\hline $\mathrm{Cl}$ & Plasma clearance \\
\hline $\mathrm{Cl}_{\text {renal }}$ & Renal clearance \\
\hline $\mathrm{C}_{\max }$ & Peak plasma concentration \\
\hline DPM & Disintegrations per minute \\
\hline
\end{tabular}


LC-MS/MS Liquid chromatography with tandem mass spectrometry detection

\section{LRI Lactated ringer's infusion}

LSC Liquid scintillation counting

$\mathrm{M}_{\mathrm{wt}} \quad$ Molecular weight

PS Performance status

SD Standard deviation

$\mathrm{t}_{1 / 2} \quad$ Terminal half-life

$\mathrm{T}_{\max } \quad$ Time to reach $\mathrm{C}_{\max }$

TRA Total radioactivity

$\mathrm{V}_{\mathrm{ss}} \quad$ Volume of distribution at steady state

WHO World Health Organization

\section{Introduction}

The taxanes paclitaxel and docetaxel are important anticancer drugs [1]. However, their use is complicated by low oral bioavailability and the development of resistance due to MDR1 over-expression or $\beta$-tubulin mutation $[2,3]$. A search for microtubule stabilizing agents with improved characteristics compared to taxanes led to the discovery of epothilone $\mathrm{A}$ and $\mathrm{B}$ in extracts of the myxobacterium Sorangium cellulosum [3], which were subsequently shown to bind to tubulin at the same binding site as paclitaxel [4]. In vitro, epothilone B was more active than in vivo (mouse models) [5], and in vivo hydrolysis of the lactone ring was suspected of producing inactive metabolites. To improve the metabolic stability of the naturally occurring epothilones, these were modified by replacing the ester bond with an amide bond [6,7]. In general, lactam analogues displayed tubulin-polymerizing and cytotoxic potencies inferior to their naturally occurring counterparts. The exception to this rule was the lactam analogue of epothilone B, ixabepilone (BMS-247550, NSC 71028, EpoB-lactam, aza-EpoB, 15-desoxy-15-aza-epothilone B), see Fig. 1 for structure [6]. Ixabepilone has undergone a number of phase II clinical trials with varying schedules at doses from 6 to $40 \mathrm{mg} / \mathrm{m}^{2}$ administered as an intravenous infusion over 1 to $3 \mathrm{~h}$ [8-11]. Response rates in metastatic breast (12-44\%), non-small cell lung (14\%), hormone-refractory metastatic

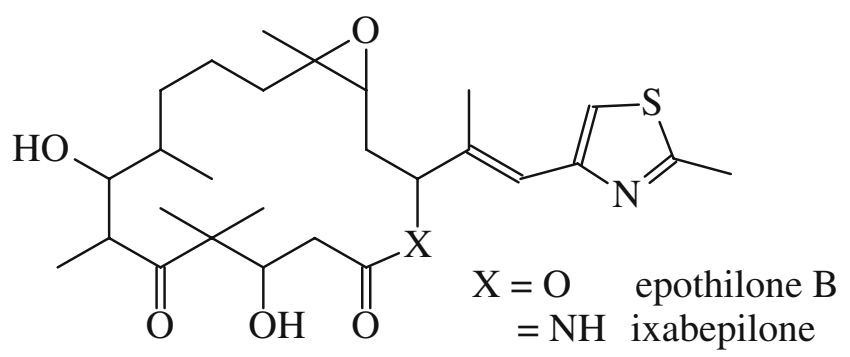

Fig. 1 Chemical structures of epothilone B and its lactam analogue ixabepilone prostate cancer $(33 \%)$, and metastatic renal cell carcinoma $(14 \%)$ were modest to promising and warrant further investigation [8]. The pharmacokinetics of ixabepilone have been described $[9,12,13]$ and the contribution of two known chemical degradation products was shown to be negligible [14], however, other than that it is a CYP3A4/5 substrate [15], little is known about the excretion and metabolic fate of ixabepilone.

The present investigation was aimed at determining the pharmacokinetics and excretory pathways of $\left[{ }^{14} \mathrm{C}\right]$ ixabepilone. To this end, we initiated a mass balance study of ixabepilone in humans. A mass balance is an elaborate pharmacokinetic investigation employing a radioactive tracer. It investigates the plasma pharmacokinetics and excretion of both the unchanged drug and the total radioactivity (drug and metabolites), and allows elucidation of the metabolic fate of a drug. The main objective is the maximum recovery of the radioactive dose in urine and faeces [16]. Due to autoradiolysis, $\left[{ }^{14} \mathrm{C}\right]$ ixabepilone at a typical specific activity of $1.5 \mu \mathrm{Ci} / \mathrm{mg}$ was unstable. However, $\left[{ }^{14} \mathrm{C}\right]$ ixabepilone at a specific activity of less than $10 \mathrm{nCi} / \mathrm{mg}$ was found to be stable. Therefore a study was conducted with a low radioactive dose of $80 \mathrm{nCi}$ of ${ }^{14} \mathrm{C}$-ixabepilone, as opposed to a more typical human radiotracer dose of circa $100 \mu \mathrm{Ci}$ dosed in study. For detection of these very low levels of radioactivity we used an ultrasensitive detection method, Accelerator Mass Spectrometry (AMS) [17-19], which measures the amount of ${ }^{14} \mathrm{C}$ as if it were a stable isotope label instead of measuring its decay. AMS separates elemental isotopes through differences in mass, charge, and energy, resulting in a $\left[{ }^{14} \mathrm{C}\right] /\left[{ }^{12} \mathrm{C}\right]$ isotope ratio. Subtracting the natural $\left[{ }^{14} \mathrm{C}\right]$ background level and taking into account the total carbon content of the sample results in a total $\left[{ }^{14} \mathrm{C}\right]$ amount that is converted to a conventional unit for radioactivity (DPM, Bq, or Ci). Given the very low dose of radioactivity administered $(80 \mathrm{nCi}$ compared to $100 \mu \mathrm{Ci}$ in a typical radio-tracer study), administration would result in negligible radiation exposure.

\section{Materials and methods}

\section{Study design}

This was an open-label, single-dose study in which eight patients with histologically confirmed solid tumours received an intravenous fixed dose of $70 \mathrm{mg}, 80 \mathrm{nCi}\left[{ }^{14} \mathrm{C}\right]$ ixabepilone over $3 \mathrm{~h}$. The protocol and informed consent form were reviewed and approved by the Institutional Review Board of the Antoni van Leeuwenhoek Hospital/ The Netherlands Cancer Institute, and each patient gave written informed consent before receiving the study medication. Eligibility criteria most relevant to the mass 
balance study were: availability for in-house admittance during the first 8 days, adequate hepatic and renal function, a performance status (PS) of 0-2, and a life expectancy of at least 12 weeks.

\section{Patients}

Eight patients (three male and five female) with a median age of 54.5 years and a WHO performance status of $0-2$ were enrolled in the study. All patients had advanced cancer for which no standard anti-cancer therapy was available. The primary tumours were: squamous cell carcinoma, colon cancer $(n=2)$, gastric carcinoma, ovarian cancer, non-small cell lung cancer, sigmoid adenocarcinoma, and pancreas carcinoma.

\section{Study medication}

Individual vials of radiolabeled ixabepilone contained $20 \mathrm{mg}, 22.8 \mathrm{nCi}\left[{ }^{14} \mathrm{C}\right]$ ixabepilone (specific activity $1.14 \mathrm{nCi} / \mathrm{mg}$ ). The $\left[{ }^{14} \mathrm{C}\right]$ ixabepilone was synthesized by Bristol-Myers Squibb by growing the myxobacterium Sorangium cellulosum in ${ }^{14} \mathrm{C}$ containing medium. This resulted in labeling throughout the ixabepilone molecule. Radiochemical and chemical purity was confirmed at $>99 \%$. Vials were reconstituted using $10 \mathrm{ml}$ Cremophor ${ }^{\circledR}$ EL:ethanol $(1: 1, \mathrm{v} / \mathrm{v})$ each. A $35 \mathrm{ml}$ volume of the reconstituted $\left[{ }^{14} \mathrm{C}\right]$ ixabepilone was added to $140 \mathrm{ml}$ Lactated Ringer's Infusion (LRI). After mixing, a $2 \mathrm{ml}$ sample was taken for quantitation of radioactivity by liquid scintillation counting (LSC). LSC radioactivity values were recalculated to amounts of $\left[{ }^{14} \mathrm{C}\right]$ ixabepilone for use in calculating recovery from feces and urine. After the 3$\mathrm{h}$ intravenous administration, infusion lines were flushed with $500 \mathrm{ml}$ LRI. Gravimetric measurements of the infusion flask prior to, and after administration enabled calculation of the amount of radioactivity actually administered. To prevent Cremophor ${ }^{\circledR}$ EL-related hypersensitivity reactions, patients were pre-medicated with oral $\mathrm{H}_{1}$ and $\mathrm{H}_{2}$ blockers.

\section{Sample collection}

Blood was collected at 0 (pre-dose), 1.5, 3 (prior to end of infusion), 3.25, 3.5, 3.75, 4, 5, 6, 8, 12, 24, 48, 72, 120, and $168 \mathrm{~h}$ after start of infusion. An indwelling catheter contralateral to the administration site was used for serial blood sampling. Separate, but simultaneous, blood samples were taken for the quantitation of total radioactivity and unchanged ixabepilone, respectively. Plasma was obtained by immediate centrifugation of the blood $(10 \mathrm{~min}, 1000 \times \mathrm{g}$, $4^{\circ} \mathrm{C}$ ). The plasma layer was aspirated and stored below $-20^{\circ} \mathrm{C}$ until analysis. We collected complete urinary and faecal output up to 7 days after administration. Urine was collected over 24-h intervals in refrigerated collection jugs. At the end of each collection interval, the respective urine samples were mixed and total volume was recorded. Aliquots were stored below $-20^{\circ} \mathrm{C}$ until analysis. Faecal samples were collected and stored at $-20^{\circ} \mathrm{C}$ per portion and combined per 24-h interval. Faeces were homogenized after addition of water $(2: 1, \mathrm{w} / \mathrm{w})$. Aliquots were stored below $-20^{\circ} \mathrm{C}$ until analysis.

AMS analysis of total radioactivity (TRA) in plasma, urine and faeces

TRA in plasma, urine and faeces was determined using AMS (Exceleron, York, UK) [20, 21]. Briefly, sample pretreatment consisted of the conversion of the carbon within the samples to graphite via a two-step process of oxidation and reduction [22]. Oxidation (combustion) was performed by heating the dried sample with copper oxide under vacuum at $900^{\circ} \mathrm{C}$ for $2 \mathrm{~h}$ in a heat-sealed tube. Reduction (graphitisation) was performed by heating the carbon dioxide formed from the oxidised sample with zinc, titanium hydride and cobalt at $500^{\circ} \mathrm{C}$ for $4 \mathrm{~h}$, followed by a further $6 \mathrm{~h}$ at $550^{\circ} \mathrm{C}$. After the graphitisation process, the graphite was pressed into a cathode. In the AMS-procedure, this cathode was bombarded with high-energy caesium $\left(\mathrm{Cs}^{+}\right)$ions. The resulting negative carbon ion beam was introduced into the AMS instrument, accelerated by an electric field of 4.5 MV, and the carbon atoms were stripped of their valency electrons. This resulted in separation of the carbon isotopical elements as $\mathrm{C}^{4+}$ ions. The carbon isotopes ${ }^{12} \mathrm{C}$ and ${ }^{13} \mathrm{C}$ were quantitated using Faraday cups, while ${ }^{14} \mathrm{C}$ was quantitated by a gas ionization detector. Because AMS provides an isotope ratio that is $\left[{ }^{14} \mathrm{C}\right] /\left[{ }^{12} \mathrm{C}\right]$ and not an absolute value, it is necessary to know the carbon content of the sample plus any added carrier. This was determined using a carbon, hydrogen, nitrogen analyser (Elemental Microanalysis Ltd., Okehampton, UK). The natural background $\left[{ }^{14} \mathrm{C}\right] /\left[{ }^{12} \mathrm{C}\right]$ level per matrix was subtracted to obtain the amount of ixabepilone-related ${ }^{14} \mathrm{C}$. The total carbon content and the specific activity of $\left[{ }^{14} \mathrm{C}\right]$ ixabepilone was used to convert the $\left[{ }^{14} \mathrm{C}\right] /\left[{ }^{12} \mathrm{C}\right]$ ratio to ixabepilone equivalents ( $\mathrm{ng} / \mathrm{ml}$ sample or $\%$ of dose). Using this sophisticated technique, it was possible to quantitate $<4$ $\mathrm{DPM} / \mathrm{ml}$ plasma, $0.01 \mathrm{DPM} / \mathrm{ml}$ urine and $0.1 \mathrm{DPM} / \mathrm{g}$ faeces (1 DPM corresponds to $395 \mathrm{ng}\left[{ }^{14} \mathrm{C}\right]$ ixabepilone).

Analysis of ixabepilone in plasma and urine

Concentrations of ixabepilone parent drug in plasma and urine were determined with a validated liquid chromatography assay equipped with tandem mass spectrometric detection (Bristol-Myers Squibb, Princeton, NJ). Briefly, 


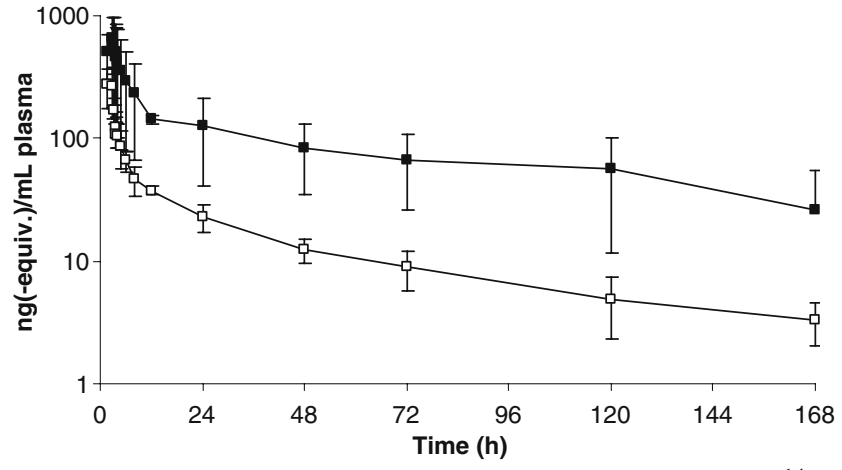

Fig. 2 Mean $( \pm \mathrm{SD})$ plasma concentration-time curves of $\left[{ }^{14} \mathrm{C}\right]$ ixabepilone derived radioactivity (filled square) and unchanged $\left[{ }^{14} \mathrm{C}\right]$ ixabepilone (open square) for eight patients

after addition of internal standard (BMS-212188) to $0.2 \mathrm{ml}$ of each sample, calibration standard and quality control sample, the samples were precipitated with acetone. The supernatant was further extracted with 1-chlorobutane. The organic layer was removed and evaporated to dryness. The residue was reconstituted and injected into the LC-MS/ MS system. Chromatographic separation was achieved, isocratically, on a YMC ODS-AQ column $(4.6 \times 50 \mathrm{~mm}$ internal diameter) at a flow rate of $0.3 \mathrm{ml} / \mathrm{min}$ with detection by electrospray tandem mass spectrometry. The mobile phase contained acetonitrile- $0.01 \mathrm{M}$ ammonium acetate $(\mathrm{pH} 5.0)(65: 35, \mathrm{v} / \mathrm{v})$. The standard curve, which ranged from 2 to $500 \mathrm{ng} / \mathrm{ml}$, was constructed with a $1 / \mathrm{x}$ weighted quadratic regression model. The within-run precision for ixabepilone in plasma and urine was within 15 and $9 \%$, respectively. The between-run precision for ixabepilone in plasma and urine was within 13 and $9 \%$, respectively. The accuracy was within 11 and $6 \%$ of the nominal values in plasma and urine, respectively.

Pharmacokinetic analyses

The pharmacokinetic analyses of the ixabepilone plasma concentration versus time data were performed by noncompartmental methods using Kinetica Version 4.2 (InnaPhase Corporation, Philadelphia, PA). The peak plasma concentration $\left(\mathrm{C}_{\max }\right)$ and the time to reach maximal concentration $\left(\mathrm{T}_{\max }\right)$ represent observed values. The area under the plasma concentration versus time curve (AUC) was calculated using a combination of linear and log trapezoidal summations. The AUC was extrapolated to infinity $\left(\mathrm{AUC}_{\text {inf }}\right)$ by dividing the last measurable concentration by the terminal rate constant, $k$. The absolute value of $k$ was used to estimate the apparent terminal half-life, $t_{1 / 2}=\ln 2 / k$. The total body clearance $(\mathrm{Cl})$ was determined by dividing dose by $\mathrm{AUC}_{\mathrm{inf}}$ and the volume of distribution at steadystate (Vss) was calculated as dose $\times$ area under the moment curve $\left(\mathrm{AUMC}_{\text {inf }}\right) /\left(\mathrm{AUC}_{\mathrm{inf}}\right)^{2}$ with appropriate corrections for infusion duration. Renal clearance was calculated by dividing amount excreted by the AUC. Similarly, pseudopharmacokinetic parameters were calculated for TRA.

Outliers were statistically assessed using Dixon's Q test.

\section{Results}

To evaluate the pharmacokinetics and excretory pathways of $\left[{ }^{14} \mathrm{C}\right]$ ixabepilone, we performed a mass balance study in

Table 1 Plasma pharmacokinetic parameters of ixabepilone and total radioactivity in cancer patients after a $3 \mathrm{~h}$ intravenous infusion of $70 \mathrm{mg}$, $80 \mathrm{nCi}\left[{ }^{14} \mathrm{C}\right]$ ixabepilone

\begin{tabular}{|c|c|c|c|c|c|c|c|c|c|c|c|}
\hline \multirow[t]{2}{*}{$\mathrm{Nr}$} & \multicolumn{6}{|c|}{ Ixabepilone } & \multicolumn{4}{|c|}{ Radioactivity (ixabepilone equiv.) } & \multirow[t]{2}{*}{$\mathrm{AUC}_{\text {last }}$ ratio $^{\mathrm{a}}$} \\
\hline & $\begin{array}{l}\mathrm{C}_{\max } \\
(\mathrm{ng} / \mathrm{ml})\end{array}$ & $\begin{array}{l}\mathrm{AUC}_{\text {last }} \\
\left(\mu \mathrm{g}^{*} \mathrm{~h} / \mathrm{ml}\right)\end{array}$ & $\begin{array}{l}\mathrm{AUC}_{\text {inf }} \\
(\mu \mathrm{g} * \mathrm{~h} / \mathrm{ml})\end{array}$ & $t_{1 / 2}(\mathrm{~h})$ & $\mathrm{Cl}(1 / \mathrm{h})$ & $\mathrm{V}_{\mathrm{ss}}(1)$ & $\begin{array}{l}\mathrm{C}_{\max } \\
(\mathrm{ng} / \mathrm{ml})\end{array}$ & $\begin{array}{l}\mathrm{AUC}_{\text {last }} \\
(\mu \mathrm{g} * \mathrm{~h} / \mathrm{ml})\end{array}$ & $\begin{array}{l}\mathrm{AUC}_{\mathrm{inf}} \\
(\mu \mathrm{g} * \mathrm{~h} / \mathrm{ml})\end{array}$ & $t_{1 / 2}(\mathrm{~h})$ & \\
\hline 1 & 277 & 3.06 & 3.35 & 51.7 & 20.9 & 1275 & 322 & 1.89 & 1.96 & 8.3 & $1.62^{\mathrm{b}}$ \\
\hline 2 & 287 & 2.75 & 2.97 & 53.0 & 23.6 & 1174 & 497 & 11.0 & 11.8 & 48.7 & 0.25 \\
\hline 3 & 433 & 2.83 & 2.99 & 51.7 & 23.4 & 929 & 681 & 10.9 & 11.3 & 36.5 & 0.26 \\
\hline 4 & 486 & 3.82 & 4.32 & 67.4 & 16.2 & 1027 & 940 & 20.1 & 21.6 & 46.9 & 0.19 \\
\hline 5 & 266 & 2.42 & 2.52 & 23.5 & 27.8 & 756 & 503 & 20.0 & 44.3 & 185.2 & 0.12 \\
\hline 6 & 273 & 2.17 & 2.29 & 36.7 & 30.5 & 912 & 573 & 11.9 & 16.3 & 99.8 & 0.18 \\
\hline 7 & 201 & 2.25 & 2.49 & 71.5 & 28.1 & 1520 & 449 & 8.53 & 9.59 & 61.2 & 0.26 \\
\hline 8 & 187 & 1.93 & 2.22 & 47.2 & 31.6 & 1635 & 1502 & 32.5 & 34.4 & 34.4 & 0.06 \\
\hline Mean & 301 & 2.65 & 2.89 & 50.3 & 25.3 & 1154 & 683 & $16.4^{\mathrm{b}}$ & $21.3^{\mathrm{b}}$ & $73.1^{\mathrm{b}}$ & $0.19^{\mathrm{b}}$ \\
\hline SD & 105 & 0.60 & 0.69 & 15.4 & 5.2 & 308 & 378 & $8.44^{\mathrm{b}}$ & $13.2^{\mathrm{b}}$ & $54.0^{\mathrm{b}}$ & $0.08^{\mathrm{b}}$ \\
\hline
\end{tabular}

${ }^{\mathrm{a}} \mathrm{AUC} \mathrm{C}_{\text {last }}$ ratio is calculated by dividing $\mathrm{AUC}_{\text {last }}$ ixabepilone by $\mathrm{AUC}_{\text {last }} \mathrm{TRA}$ and expresses the relative contribution of ixabepilone to TRA exposure in plasma.

${ }^{\mathrm{b}}$ Patient 1 was not included in the calculation because the radioactivity AUC and $t_{1 / 2}$ could not be determined accurately (see text). This also resulted in the deviating $\mathrm{AUC}_{\text {last }}$ ratio (outlier). 


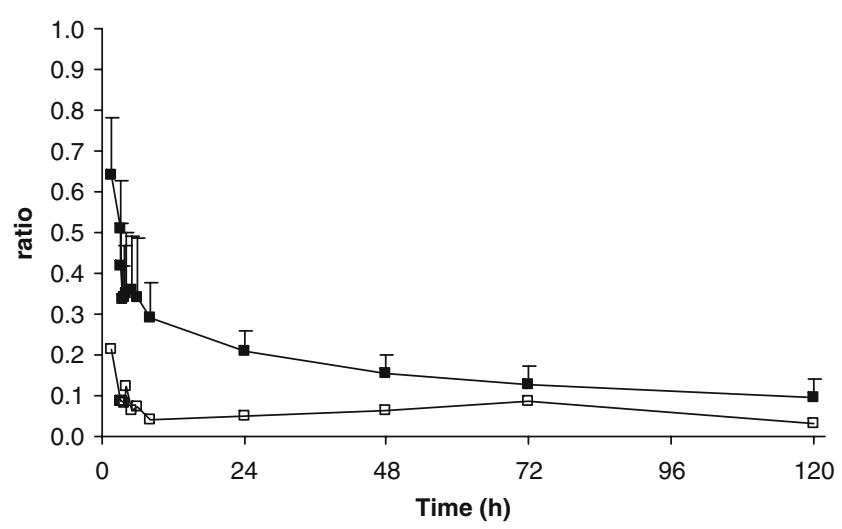

Fig. 3 Mean $(+\mathrm{SD})\left[{ }^{14} \mathrm{C}\right]$ ixabepilone to total radioactivity ratio in plasma over time for patients 1-7 (filled square) and patient 8 (open square)

eight patients. Figure 2 shows the mean plasma concentrations over time of both TRA and ixabepilone as determined by AMS and LC-MS/MS, respectively.

Both TRA and ixabepilone in plasma exhibited an initial distribution phase of approximately $10 \mathrm{~h}$ followed by a much slower terminal elimination phase with half-lives of 73.1 and $50.3 \mathrm{~h}$, respectively. The time to maximum plasma concentration was typically around the end of infusion. Plasma ixabepilone concentrations were quantifiable through $168 \mathrm{~h}$ in all patients and plasma TRA concentrations were quantifiable through $168 \mathrm{~h}$ in all patients except in patient 1 in whom plasma TRA concentrations were only quantifiable for $48 \mathrm{~h}$. Pharmacokinetic parameters are summarized in Table 1. The ratio of the ixabepilone AUC to the total radioactivity AUC, or AUC-ratio, is a measure of exposure to $\left[{ }^{14} \mathrm{C}\right]$ ixabepilone relative to total $\left[{ }^{14} \mathrm{C}\right]$ ixabepilone related compounds. The AUC ratio of patient 1 was larger than unity. This was caused by the underestimated TRA AUC, which was based on measurements until only $48 \mathrm{~h}$, after which plasma concentrations fell below the lower limit of quantitation. Besides the TRA

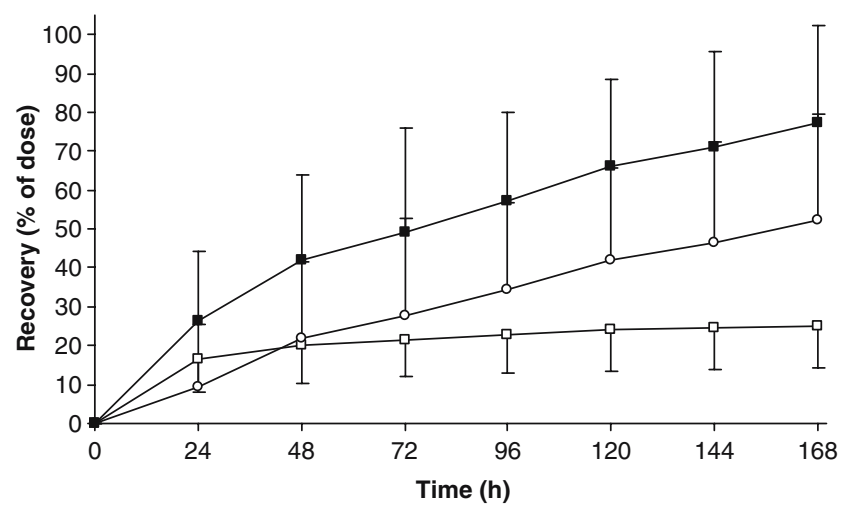

Fig. 4 Mean urinary (open square, -SD), faecal (open circle, +SD) and total (filled square, $+\mathrm{SD})$ cumulative excretion $(168 \mathrm{~h})$ of $\left[{ }^{14} \mathrm{C}\right]$ ixabepilone derived radioactivity for eight patients
AUC, the $t_{1 / 2}$ of patient 1 was also inaccurately estimated at $8.3 \mathrm{~h}$. Therefore, patient 1 was omitted from calculation of mean plasma TRA parameters. Figure 3 shows the plasma concentrations of ixabepilone relative to TRA for patients 1-7 and patient 8 . Patient 8 experienced a blocked bile duct (reflected by a maximum plasma bilirubin concentration of $47 \mu \mathrm{mol} / \mathrm{l}(3 \times$ upper limit of normal $)$ and alkaline phosphatase of $500 \mathrm{U} / 1(4 \times$ upper limit of normal) at day 7) resulting in a higher plasma TRA, $\mathrm{C}_{\max }$ and AUC. The higher TRA plasma concentrations in patient 8 resulted in an AUC ratio of plasma ixabepilone to TRA that was lower than that of the other patients. In contrast, unchanged ixabepilone plasma pharmacokinetics were not affected in this patient.

Figure 4 displays the mean excretion of TRA in urine and faeces and the total, in time, and Fig. 5 displays the mean cumulative urinary excretion of $\left[{ }^{14} \mathrm{C}\right]$ ixabepilone derived radioactivity and unchanged $\left[{ }^{14} \mathrm{C}\right]$ ixabepilone. Table 2 shows individual $168 \mathrm{~h}$ excretions of $\left[{ }^{14} \mathrm{C}\right]$ ixabepilone and TRA in urine and faeces. The U/F ratio is the ratio of urinary recovery relative to faecal recovery. Patient 3 displayed a rather low recovery of radioactivity from both urine (14.8\%) and faeces (38.3\%). Plasma pharmacokinetics were not different compared to the other patients. A low total recovery of $37.8 \%$ was also obtained for patient 4 , attributable to a very low faecal recovery (12.7\%), while urinary recovery was normal (25.1\%). This patient only defecated at $24 \mathrm{~h}$ and at $168 \mathrm{~h}$ (a few grams), which almost certainly explains the observed low recovery. Although the plasma pharmacokinetics and urinary excretion did not deviate extremely from the other patients, patient 4 displayed a somewhat elevated plasma exposure to both radioactivity and ixabepilone, and the lowest clearance for unchanged ixabepilone. If we now look at the $U / F$ ratios (a measure of urinary versus faecal elimination), patient 4 , who had the low fecal output, is an outlier $(Q=0.86$, critical value $p=0.05: 0.57)$ compared

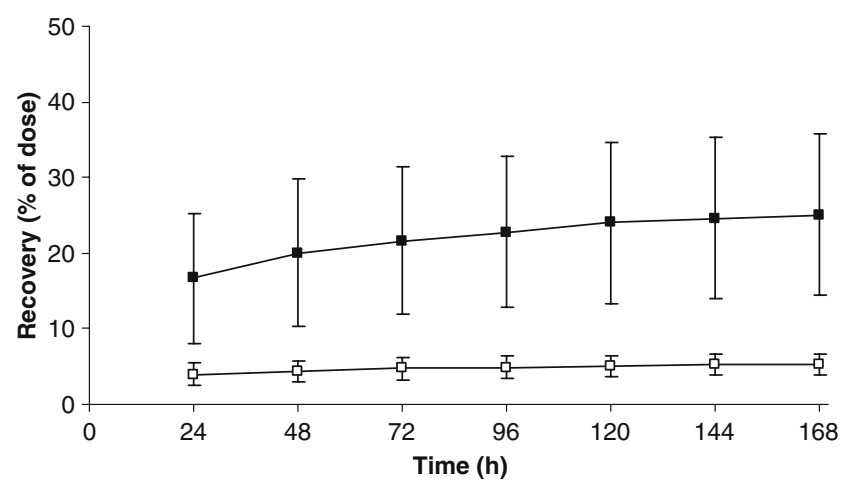

Fig. 5 Mean $( \pm \mathrm{SD})$ cumulative urinary excretion of $\left[{ }^{14} \mathrm{C}\right]$ ixabepilone derived radioactivity ( filled square) and unchanged $\left[{ }^{14} \mathrm{C}\right]$ ixabepilone (open square) for eight patients 
Table 2 Urinary and faecal recovery $(0-168 \mathrm{~h})$ of ixabepilone and total radioactivity in cancer patients after a $3 \mathrm{~h}$ intravenous infusion of $70 \mathrm{mg}$, $80 \mathrm{nCi}\left[{ }^{14} \mathrm{C}\right]$ ixabepilone

\begin{tabular}{|c|c|c|c|c|c|c|}
\hline \multirow[t]{3}{*}{$\mathrm{Nr}^{\mathrm{a}}$} & \multicolumn{4}{|c|}{ Recovery (\% of dose) } & \multirow[t]{3}{*}{ Radioactivity $\left(\mathrm{U} / \mathrm{F}\right.$ ratio $\left.^{\mathrm{c}}\right)$} & \multirow[t]{3}{*}{ Ixabepilone $\left(\mathrm{Cl}_{\text {renal }}(1 / \mathrm{h})\right)$} \\
\hline & \multirow{2}{*}{$\begin{array}{l}\text { Ixabepilone } \\
\text { Urine }\end{array}$} & \multicolumn{3}{|c|}{ Total radioactivity } & & \\
\hline & & Urine & Faeces & Total & & \\
\hline 1 & 5.07 & 14.56 & 59.69 & 74.25 & 0.24 & 1.16 \\
\hline 2 & 4.66 & 23.28 & 74.78 & 98.06 & 0.31 & 1.19 \\
\hline 3 & 7.76 & 14.77 & 38.29 & 53.06 & 0.39 & 1.92 \\
\hline 4 & 3.32 & 25.08 & 12.71 & 37.79 & 1.97 & 0.61 \\
\hline 5 & 5.46 & 19.66 & 65.02 & 84.68 & 0.30 & 1.58 \\
\hline 6 & 6.12 & 30.78 & 64.59 & 95.37 & 0.48 & 1.98 \\
\hline 7 & 6.03 & 25.05 & 86.72 & 111.77 & 0.29 & 1.87 \\
\hline 8 & 4.02 & 47.65 & 15.62 & 63.27 & 3.05 & 1.46 \\
\hline Mean & 5.30 & 25.10 & 52.18 & 77.28 & $0.33^{\mathrm{b}}$ & 1.47 \\
\hline SD & 1.38 & 10.63 & 27.17 & 24.94 & $0.08^{\mathrm{b}}$ & 0.47 \\
\hline
\end{tabular}

\footnotetext{
${ }^{a}$ Patients 1,2 , and 8 were male.

${ }^{\mathrm{b}}$ Patient 4 was not included because of the extremely low production of faeces and patient 8 was not included in the calculation because his bile duct obstruction (relevance illustrated by increasing plasma bilirubin concentrations) may have reduced faecal excretion.

${ }^{c}$ The $\mathrm{U} / \mathrm{F}$ ratio is the ratio of urinary recovery relative to faecal recovery.
}

to patients $1,2,3,5,6$ and 7 . Patient 8 , who experienced the blocked bile duct stent, is also an outlier $(Q=0.91$, critical value $p=0.05$ : 0.52 ) compared to the same patients. The urinary recovery of patient 8 was highest at $47.7 \%$ causing the large standard deviation of urinary recovery. However, the urinary recovery of unchanged ixabepilone of $4.0 \%$ was within the normal range. The faecal recovery of this patient was the lowest (excluding patient 4) at 15.6\%. Apparently, there was no accumulation of the active drug despite a decreased biliary excretion.

On average, more than $77 \%$ of the drug was excreted over the 7-day period with the majority of $52 \%$ being excreted in faeces and $25 \%$ in urine. Excretion in faeces occurred at a relatively constant rate over the entire collection period, with only 10 and $12 \%$ of dose recovered in the $0-24$ and $24-48 \mathrm{~h}$ collection intervals, respectively. In contrast, urinary excretion displayed two distinct phases with $65 \%$ of total urinary radioactivity (corresponding to $17 \%$ of dose) and $76 \%$ of total urinary ixabepilone being excreted in the first $24 \mathrm{~h}$. From 24 to $168 \mathrm{~h}$, urinary excretion occurred at a relatively slow constant rate. This may reflect the biphasic plasma curve, with high concentrations in the distribution phase and lower concentrations in the terminal elimination phase. At first urinary excretion predominates and after $24 \mathrm{~h}$, faecal excretion becomes the dominant route of excretion.

\section{Discussion}

The present investigation was aimed at determining the pharmacokinetics and excretory pathways of $\left[{ }^{14} \mathrm{C}\right]$ ixabepilone by performing a mass balance study.
In conventional human mass balance studies, approximately $100 \mu \mathrm{Ci}$ of $\left[{ }^{14} \mathrm{C}\right]$ is typically used to trace the fate of a drug [16]. Due to autoradiolysis of ixabepilone, this level of labeling was not possible. The level of radioactive labeling we used was more than 1,000-fold lower at $80 \mathrm{nCi}$. The most commonly used method for detection of radiotracers in mass balance studies is liquid scintillation counting (LSC). This method however, relies on the detection of $\beta$-emissions and therefore can only exploit a very small proportion of the isotope. ${ }^{14} \mathrm{C}$ has a half-life of 5740 years and therefore only about $0.012 \%$ of the ${ }^{14} \mathrm{C}$ atoms in a sample decay over the course of a year. AMS however, is a nuclear physics technique that detects the individual ${ }^{14} \mathrm{C}$ atoms, as if they were stable isotopes, and is therefore much more sensitive than LSC [19]. Originally, AMS technology was developed in the 1970s for radiocarbon dating, but has recently found novel uses in biomedical research. It has been used to study DNA adducts of carcinogens, and it can replace decay counting as a method of analysis in biological samples [17, 23-25]. A first human mass balance using this ultra-sensitive technique has already been reported and is expected to be followed by many others [26].

The ixabepilone plasma pharmacokinetic parameters observed in the present investigation are similar to the values previously reported for a standard phase I dose escalation study in which 11 patients were administered $40 \mathrm{mg} / \mathrm{m}^{2}$ of ixabepilone in an expansion of the recommended phase II dose [9]. However, in our study, the coefficient of variation for $\mathrm{AUC}_{\text {inf }}$ and $\mathrm{Cl}$ of ixabepilone was 24 and $21 \%$ as compared to 46 and $38 \%$ in the phase I dose escalation study. The lower inter-patient variability may 
result from the greater rigor toward sample collection and processing that is possible in a mass balance study during which the patient is hospitalized. It should also be noted that the administration of ixabepilone as a flat $70 \mathrm{mg}$ dose in the present study did not result in any increase in inter-patient variability compared with the dose, based on body surface area, which was administered during the phase I study.

Our results show that ixabepilone is extensively metabolised. This is indicated by the plasma AUC ratio of 0.19 and confirmed by the recovery of ixabepilone relative to TRA in urine of approximately 0.21 . Patient 8 experienced a blocked bile duct resulting in a higher plasma TRA, $\mathrm{C}_{\max }$ and AUC, but interestingly, unchanged ixabepilone plasma pharmacokinetics were not affected and excretion of ixabepilone metabolites was re-routed to urine.

The calculated half-life of TRA was longer than that of ixabepilone ( $t_{1 / 2}$ of 73.1 and $50.3 \mathrm{~h}$ respectively), however, we do not conclude that TRA was eliminated more slowly than ixabepilone. Comparison of ixabepilone and TRA half-lives per patient revealed that in 5 cases (patient 2, 3, 4, 7, and 8 ) the TRA half-life was shorter than the ixabepilone half-life. The mean TRA half-life was disproportionally influenced by the long half-life observed in patient 5 $(185 \mathrm{~h})$. The very long half-life of TRA in this patient is not likely to be clinically relevant because this patient excreted $85 \%$ of the dose within 7 days. Based on the half-lives for plasma radioactivity observed in the other patients, in the once every 3 weeks administration schedule, accumulation of metabolites should not occur. The seemingly long ixabepilone half-life of over $50 \mathrm{~h}$ is not unusual when compared to other tubulin-interacting drugs. Half-lives of e. g. vinca-alkaloids range from $12-42 \mathrm{~h}$ for vindesine and up to a half-life of several days for vincristine.

With an average recovery of $77 \%$ of the drug excreted over the 7-day period, the recovery of radioactivity of this mass balance study is reasonably good [16]. The incomplete recovery is explained by the still ongoing excretion at the end of the 7 day collection period, and the long plasma half-life of TRA. Immediate assessment of the still appreciable amounts of radioactivity excreted on day 7 to possible extend the period of collecting excreta, as suggested in the literature [16], was not possible. The shipping and lagtime in quantitating radioactivity by AMS precluded this. Another contributing route of elimination not monitored in the current study is loss of radioactivity through expiration of ${ }^{14} \mathrm{C} \mathrm{O}_{2}$ [16]. At $52 \%$ of the dose versus $25 \%$, faecal excretion is a quantitatively more important route of elimination than urinary excretion. Biliary excretion is governed by a molecular weight limit. In humans, polar compounds with a molecular weight above approximately $500 \mathrm{~g} / \mathrm{mol}$ are predominantly excreted via bile [27, 28]. Ixabepilone metabolites will probably be more polar (phase I metabolism, oxidation, hydrolysis etc.) and have higher masses (conjugates or phase II metabolites) than ixabepilone $\left(\mathrm{M}_{\mathrm{wt}} 506.7 \mathrm{~g} / \mathrm{mol}\right.$, and rather hydrophobic). Whether this is the case for ixabepilone remains to be investigated by metabolic profiling of the excreta.

Given the normal ixabepilone plasma concentrations of patient 8 while experiencing a blocked bile duct, biliary excretion of unchanged ixabepilone into faeces may not be a very important elimination route, and the results suggest that ixabepilone was equally well metabolised but that the biliary excretion of these metabolites was hindered by the blocked bile duct stent, resulting in a shift to urinary excretion of total radioactivity.

The importance of metabolism in the elimination of ixabepilone has been confirmed by this study as apparent from the low contribution of unchanged ixabepilone to TRA in plasma and urine. Ixabepilone related radioactivity is predominantly excreted in the faeces. Future investigations must be aimed at elucidating the metabolic fate of ixabepilone, and determining the activity of the metabolites. Subsequent identification of drug metabolizing enzymes involved in ixabepilone metabolism may result in explaining pharmacokinetic variability of ixabepilone in individual patients.

\section{References}

1. Rowinsky EK (1997) The development and clinical utility of the taxane class of antimicrotubule chemotherapy agents. Annu Rev Med 48:353-374

2. Felip E (2002) New anti-tubulin agents. Suppl Tumori 1:S17-S18

3. Bollag DM, McQueney PA, Zhu J, Hensens O, Koupal L, Liesch J, Goetz M, Lazarides E, Woods CM (1995) Epothilones, a new class of microtubule-stabilizing agents with a taxol-like mechanism of action. Cancer Res 55:2325-2333

4. Nettles JH, Li H, Cornett B, Krahn JM, Snyder JP, Downing KH (2004) The binding mode of epothilone A on alpha,beta-tubulin by electron crystallography. Science 305:866-869

5. Giannakakou P, Sackett DL, Kang YK, Zhan Z, Buters JT, Fojo T, Poruchynsky MS (1997) Paclitaxel-resistant human ovarian cancer cells have mutant beta-tubulins that exhibit impaired paclitaxel-driven polymerization. J Biol Chem 272:17118-17125

6. Borzilleri RM, Zheng X, Schmidt RJ, Johnson JA, Kim SH, DiMarco JD, Fairchild CR, Gougoutas JZ, Lee FYF, Long BH, Vite GD (2000) A novel application of a Pd(0)-catalyzed nucleophilic substitution reaction to the regio- and stereoselective synthesis of lactam analogues of the epothilone natural products. J Am Chem Soc 122:8890-8897

7. Schinzer D, Altmann KH, Stuhlmann F, Bauer A, Wartmann M (2000) Synthesis and biological evaluation of aza-epothilones. ChemBioChem 1:67-70

8. Larkin JM, Kaye SB (2006) Epothilones in the treatment of cancer. Expert Opin Investig Drugs 15:691-702

9. Mani S, McDaid H, Hamilton A, Hochster H, Cohen MB, Khabelle D, Griffin T, Lebwohl DE, Liebes L, Muggia F, Horwitz SB (2004) Phase I clinical and pharmacokinetic study of BMS247550, a novel derivative of epothilone B, in solid tumors. Clin Cancer Res 10:1289-1298 
10. Altaha R, Fojo T, Reed E, Abraham J (2002) Epothilones: a novel class of non-taxane microtubule-stabilizing agents. Curr Pharm Des 8:1707-1712

11. Bayes M, Rabasseda X, Prous JR (2004) Gateways to clinical trials. Methods Find Exp Clin Pharmacol 26:53-84

12. Abraham J, Agrawal M, Bakke S, Rutt A, Edgerly M, Balis FM, Widemann B, Davis L, Damle B, Sonnichsen D, Lebwohl D, Bates S, Kotz H, Fojo T (2003) Phase I trial and pharmacokinetic study of BMS-247550, an epothilone B analog, administered intravenously on a daily schedule for five days. J Clin Oncol 21:1866-1873

13. McDaid HM, Mani S, Shen HJ, Muggia F, Sonnichsen D, Horwitz SB (2002) Validation of the pharmacodynamics of BMS-247550, an analogue of epothilone B, during a phase I clinical study. Clin Cancer Res 8:2035-2043

14. Aghajanian C, Burris HA III, Jones S, Spriggs DR, Cohen MB, Peck R, Sabbatini P, Hensley ML, Greco FA, Dupont J, O'connor OA (2007) Phase I study of the novel epothilone analog ixabepilone (BMS-247550) in patients with advanced solid tumors and lymphomas. J Clin Oncol 2007 Jan 29 (Epub ahead of print)

15. Goel S, Goldberg G, Iacono LC, Cohen M, Griffin T, Gollamudi R, Desai KK, Chaudhary I, Mani S (2006) Effect of ketoconazole on the pharmacokinetics and pharmacodynamics of ixabepilone (Abstract). Proc Am Soc Clin Oncol 24:80S

16. Beumer JH, Beijnen JH, Schellens JH (2006) Mass balance studies, with a focus on anticancer drugs. Clin Pharmacokinet $45: 33-58$

17. Garner RC, Barker J, Flavell C, Garner JV, Whattam M, Young GC, Cussans N, Jezequel S, Leong D (2000) A validation study comparing accelerator MS and liquid scintillation counting for analysis of 14C-labelled drugs in plasma, urine and faecal extracts. J Pharm Biomed Anal 24:197-209

18. Lappin G, Garner RC (2003) Big physics, small doses: the use of AMS and PET in human microdosing of development drugs. Nat Rev Drug Discov 2:233-240
19. Garner RC (2000) Accelerator mass spectrometry in pharmaceutical research and development - a new ultrasensitive analytical method for isotope measurement. Curr Drug Metab 1:205-213

20. Lappin G, Garner RC (2003) Ultra-sensitive detection of radiolabelled drugs and their metabolites using accelerator mass spectrometry. In: Wilson I (ed): Handbook of analytical separations, Amsterdam

21. Lappin G, Garner RC (2004) Current perspectives of 14C-isotope measurement in biomedical accelerator mass spectrometry. Anal Bioanal Chem 378:356-364

22. Vogel JS (1992) Rapid production of graphite without contamination for biomedical AMS. Radiocarbon 34:344-350

23. Garner RC (1998) The role of DNA adducts in chemical carcinogenesis. Mutat Res 402:67-75

24. Lightfoot TJ, Coxhead JM, Cupid BC, Nicholson S, Garner RC (2000) Analysis of DNA adducts by accelerator mass spectrometry in human breast tissue after administration of 2-amino-1methyl-6-phenylimidazo[4,5-b]pyridine and benzo[a]pyrene. Mutat Res 472:119-127

25. Mauthe RJ, Dingley KH, Leveson SH, Freeman SP, Turesky RJ, Garner RC, Turteltaub KW (1999) Comparison of DNA-adduct and tissue-available dose levels of MeIQx in human and rodent colon following administration of a very low dose. Int $\mathrm{J}$ Cancer 80:539-545

26. Garner RC, Goris I, Laenen AA, Vanhoutte E, Meuldermans W, Gregory S, Garner JV, Leong D, Whattam M, Calam A, Snel CA (2002) Evaluation of accelerator mass spectrometry in a human mass balance and pharmacokinetic study-experience with 14Clabeled (R)-6-[amino(4-chlorophenyl)(1-methyl-1H-imidazol-5yl)methyl]-4-(3-chlorophenyl)-1-methyl-2(1 H)-quinolinone (R115777), a farnesyl transferase inhibitor. Drug Metab Dispos 30:823-830

27. Clarke SJ, Beale PJ, Rivory LP (2000) Clinical and preclinical pharmacokinetics of raltitrexed. Clin Pharmacokinet 39:429-443

28. Rowland M, Tozer TN (1995) Clinical pharmacokineticsconcepts and applications. Williams \& Wilkins, Philadelphia, PA 